\title{
Mobil Devlet Kullanımını Etkileyen Faktörlerin Belirlenmesi: Ankara İli Örneği
}

\section{Determining Factors Affecting Mobile Government Usage: Ankara Province Case}

Vildan Ateş ${ }^{1}$ (1)

1(Dr. Öğr. Üyesi), Ankara Yıldırım Beyazıt Üniversitesi, İșletme Fakültesi, Yönetim Bilişim Sistemleri, Ankara, Türkiye

ORCID: V.A. 0000-0002-8855-8556

\section{Corresponding author:}

Vildan ATEŞ

Ankara Yıldırım Beyazıt Üniversitesi, İşletme Fakültesi, Yönetim Bilişim Sistemleri, Ankara, Türkiye

E-mail address: vgirginates@gmail.com

Submitted: 23.01 .2021

Revision Requested: 01.02.2021

Last Revision Received: 19.02.2021

Accepted: 23.02.2021

Published Online: 12.05.2021

Citation: Ates, V. (2021). Mobil devlet kullanımını etkileyen faktörlerin belirlenmesi: Ankara ili örneği. Acta Infologica, 5(1), 39-52 https://doi.org/10.26650/acin.866945
ÖZ

Kablosuz ve mobil teknolojilerde yaşanan gelişmeler halka hizmet sunmada yeni bir kanal olan mobil devlete (m-devlet) olan ilgiyi arttırmıştır. Bu doğrultuda m-devlet uygulaması üzerinden sunulan hizmetlerin kullanıcılar tarafından benimsenmesi ve kullanılması kritik öneme sahiptir. Bu çalışmanın amacı, m-devlet kullanımını etkileyen faktörlerin belirlenmesidir. Literatür taraması sonucu m-devlet kullanımını etkilediği düşünülen yedi faktörden (bilgi kalitesi, güvenlik algısı, güven, hizmet maliyeti, kullanım kolaylığı, sosyal etki, yararlılık) oluşan kuramsal model ve çalışmanın hipotezleri oluşturulmuştur. Veri toplama aracı olarak M-Devlet Kullanımı Ölçeği (M-DKÖ) geliştirilmiştir. Çalışmanın verileri Ocak 2020 tarihinde Ankara'daki üç devlet üniversitesinde öğrenim gören 183 üniversite öğrencisinden toplanmıştır. M-devlet kullanımını etkileyen faktörlerin belirlenmesi için hazırlanan ölçeğinin faktör yapısı LISREL paket programı kullanılarak analiz edilmiştir. Ölçeğin yapı güvenirliği ve yakınsama geçerliği doğrulayıcı faktör analizi (DFA) ile gerçekleştirilmiştir. Analizler sonucu kuramsal modeldeki yedi faktörün t değerleri, hata varyansları, standart katsayıları ve uyum indeksleri kontrol edilmiştir. Çalışma sonucunda kuramsal modeldeki yedi faktörden biri olan hizmet maliyeti dışındaki diğer altı faktörün m-devlet kullanımını etkilediği görülmüştür. Anahtar Kelimeler: M-Devlet, M-Devlet Kullanımı, Yapısal Eşitlik Modeli, Türkiye

\section{ABSTRACT}

The developments in wireless and mobile technologies have increased the interest in the mobile government (m-government), which is a new channel in providing services to the citizens. It is critical users adopt and use the services offered through the m-government application.The purpose of this study is to determine the factors affecting the use of m-government. As a result of the literature review, a theoretical model consisting of seven factors (information quality, security perception, trust, service cost, ease of use, social impact, usefulness) was created and hypotheses of the study were presented. M-Government Usage Scale (M-GUS) was developed as a data collection tool. The data of the study was collected from 183 university students studying in three public universities in Ankara in January 2020. The scale was prepared to determine the factors affecting the use of m-government. The factor structure was analyzed by using the LISREL package program. The construct reliability and convergence validity of the scale were performed by confirmatory factor analysis (CFA). As a result of the analysis, $t$ values, error variances, standard coefficients and fit indexes of the seven factors in the theoretical model were checked. As a result of the study, it was observed that six factors except the service cost, which is one of the seven factors in the theoretical model, affect the use of m-government.

Keywords: M-Government, Usage Of M-Government, Structural Equation Model, Turkey 


\section{GIRİŞ}

Mobil teknoloji insanların teknolojiyi kullanma biçimlerini değiştirerek sunulan hizmetlerinden her yerde ve her zaman yararlanma firsatı sunmaktadır. Bu nedenle mobil cihazlar kullanıcıya hizmet sunmada yeni bir yöntem olarak kullanılmaya başlanmıştır. Mobil teknolojilerde yaşanan bu gelişmeler mobil devlet (m-devlet) uygulamalarının geliştirilmesine yol açmıştır. M-devlet, vatandaş ve devlet arasındaki iletişimi kullanıcı hareket halinde dahi olsa hızlı bir şekilde sağlayacak şekilde uygulamaların mobil cihazlar üzerinden kullanılması olarak tanımlanabilir. M-devlet kamu hizmetlerinin sunulmasında mobil teknolojiler kullanılarak e-devlet uygulamalarının yaygınlaştırılması ve geliştirilmesi şeklinde düşünülen yeni nesil bir hizmet sunumu olarak görülmektedir. E-devletin bir alt kümesi ve tamamlayıcısı olan m-devlet, e- devlet uygulamalarını daha geniş kitlelere ulaştırabilmesi, kalitesini arttırması, zamandan tasarruf sağlaması ve kullanılabilirliğini arttırması özellikleriyle e-devleti destekleyen önemli bir unsurdur (Alotaibi, Houghton \& Sandhu, 2016).

Türkiye'de m-devlet uygulaması 2012 yılından beri kullanılmaktadır. M-devlet uygulaması içerisinde 2869 hizmet sunulmakla birlikte e-devlet kapsamında yer alan hizmetlerin tamamı bu uygulama içerisinde bulunmamaktadır (E-Devlet Portalı, 2021). 2019 yılı sonu itibarı ile e-devlet portalına genel giriş sayısı 1.179.624.439 iken bu girişlerin yaklaşık \%40’ının mobil uygulama üzerinden yapıldığı görülmektedir (Önal, 2020). Bu oran 2012 yılında sadece \% 0,5 iken sonraki yıllarda mobil uygulama üzerinden e-devlet kullanımının arttığını ve gelecek yıllarda daha da artacağı öngörülebilir. M-devlet uygulamasının özellikle genç nüfus (18-24 yaş) tarafından kullanılması ve benimsenmesi uygulamanın amacına ulaşması ve geleceği için kritik bir öneme sahiptir. Bu doğrultuda m-devlet kullanıcısı olan üniversite öğrencilerinin görüşleri alınarak m-devlet kullanımını etkileyen faktörler araştırılacaktır.

Literatür taraması sonucunda farklı ülkelerde m-devlet kullanımını etkileyen faktörler ve engellerin neler olduğunu araştıran çalışmaların olduğu görülmüştür (Abdelghaffar \& Magdy, 2012; Almarashdeh \& Alsmadi, 2017; Abu-Shanab \& Haider, 2015; Al-khamayseh, Lawrence \& Zmijewska, 2006; Hung, Chang \& Kuo, 2013; Ishengoma, Mselle \& Mongi, 2019; Roubah, Qurban, Al-Qirim \& Tarhini, 2018; Shareef, Archer \& Dwivedi, 2012; Saxena, 2017; Tan, Ooi, Sim \& Phusavat, 2012; Wang, 2014). Türkiye'de ise $m$-devlet hakkında yapılan çalışmaların çok az sayıda olduğu ve bu çalışmalarında m-devlet hizmetlerini açıklamaya yönelik olduğu görülmektedir (Arslan, 2012; Güler \& Dövertaş, 2009; Gürses \& Engin, 2016; Öztürkcan, Kasap \& Eryaysoy, 2012; Üste \& Güzel, 2012; Yıldırım \& Panayırc1, 2012). M-devlet kullanımını etkileyen faktörleri araştıran ulusal düzeyde bir çalışmanın olmaması bu araştırmanın motivasyon kaynağıdır. Buna ilaveten bu çalışma bilişim teknolojilerine daha yatkın ve yoğun kullanan 18-24 yaş aralığındaki kullanıcılar ile gerçekleştirildiği için de önemlidir.

Bu çalışmanın amacı, Ankara'daki üniversite öğrencilerinin m-devleti kullanmalarını etkileyen faktörlerin belirlenmesidir. Çalışma sonucunda m-devlet kullanımını etkileyen faktörlerin neler olduğunun belirlenmesi ve bu faktörlerin etki gücünün ortaya çıkarılması hedeflenmektedir.

Çalışma altı bölümden oluşmaktadır. İkinci bölümde literatür taraması sunulmuştur. Üçüncü bölümde ise m-devlet kullanımını etkileyebileceği düşünülen faktörler ve araştırmanın hipotezlerine yer verilmiştir. Dördüncü bölümde yöntem detaylı bir şekilde açıklandıktan sonra beşinci bölümde çalışmanın bulguları rapor edilmiştir. Altıncı bölümde çalışmanın sonucu ve önerilere yer verilmiştir.

\section{LITERATÜR TARAMASI}

Literatür taraması bölümü iki alt bölümden oluşmaktadır. İlk olarak dünyadaki farklı ülkelerde m-devlet kullanımını etkileyen faktörlerini araştıran çalışmalar sunulmuştur. İkinci bölümde de Türkiye'de m-devlet hakkında yapılan çalışmalar incelenmiştir.

Farklı ülkelerde m-devlet kullanımını etkileyen faktörlerin araştırıldığı çalışmalar görselliği arttırmak ve okunabilirliği kolaylaştırmak için Tablo 1'de sunulmuştur. Çalışmalar kronolojik olarak sıralanmıştır. Tablo 1'de görüldüğü gibi çalışmalar 2006 ila 2018 yılları arasında gerçekleştirilmiştir. Tablo 1'de bulunan tüm faktörler değerlendirildiğinde özellikle kullanışlılık, kullanım kolaylığı, risk, güven ve güvenlik faktörlerinin diğer faktörlere göre daha fazla çalışmada m-devlet kullanımını etkileyen faktörler olarak rapor edildiği görülmektedir. 
Literatür taramasının ikinci bölümünde Türkiye'de m-devlet konusunda yapılan çalışmalar incelenmiştir. Güler ve Dövertaş (2009) tarafından yapılan çalışmada Türkiye'de sunulan m-devlet hizmetleri merkezi ve yerel yönetim düzeyinde incelenmiştir. Diğer iki çalışmada da Türkiye'deki belediyelerin sunduğu m-devlet hizmetleri kullanımı hakkında olduğu görülmektedir (Arslan, 2012; Gürses \& Engin, 2016). Türkiye'deki m-devlet uygulamaları hakkında bilgiler veren bir çalışma da Üste ve Güzel (2012) tarafından gerçekleştirilmiştir. Aynı yıl Yıldırım ve Panayırcı (2012) tarafından gerçekleştirilen çalışmada Türkiye'de mobil devlete geçişteki çabalar ve yeniliklere vurgu yapılmıştır. Sadece Öztürkcan ve diğerleri (2018) tarafından yapılan çalışmada m-devlet kullanıcı kabulü açısından incelendiği görülmektedir. Bu çalışmada veriler telefon görüşmesi ile toplanmıştır. Çalışma sonucunda kullanıcıların m-devlet ile aldıkları hizmetleri cep telefonu ile oy kullanmak, vergiyi öğrenmek ve ödemek, emniyet hizmetlerine erişmek, sağlık hizmetleri almak, adres değişikliği yapmak şeklinde rapor etmişlerdir.

M-devletin vatandaş devlet iletişiminde büyük bir etkisi bulunmasına rağmen Türkiye'de m-devlet üzerine yapılan az araştırma olduğu görülmektedir. M-devlet kullanımını etkileyen faktörlerin kapsamlı bir şekilde araştırıldığı bir çalışma ise bulunmamaktadır.

Tablo 1

Önceki çalışmaların özeti

\begin{tabular}{|c|c|c|c|}
\hline Yazar/lar & Yıl & Ülke & M-Devlet Kullanımını Etkileyen Faktörler \\
\hline Alkhamayseh et al. & 2006 & Global & $\begin{array}{l}\text { Altyap1, e-devletin kabulü, gizlilik ve güvenlik, kalite, kullanıc1 } \\
\text { ihtiyaçları, kullanılabilir uygulamalar, maliyet }\end{array}$ \\
\hline Abdelghaffar \& Magdy & 2012 & Misir & Farkındalık, kullanışlılık, sosyal etki, yüz-yüze iletişim \\
\hline Shareef et al.. & 2012 & Hindistan & Empati, güvenlik, kullanım kolaylığı, sağlanan avantaj \\
\hline Tan et al. & 2012 & Malezya & Kişisel kurallar, kullanım kolaylığı, yararlılık \\
\hline Hung et al. & 2013 & Tayvan & $\begin{array}{c}\text { Dışsal etki, etkileşim, kullanışlılık, kullanım kolaylığı, kolaylaştırıcı } \\
\text { koşullar }\end{array}$ \\
\hline Wang & 2014 & Çin & Değer algısı, kullanışlılık, güven \\
\hline Abu-Shanab \& Haider & 2015 & Ürdün & $\begin{array}{c}\text { Cevap verme yeteneği, kullanışl1lık, kullanım kolaylığı, } \\
\text { uygunluk }\end{array}$ \\
\hline Alotaibi et al. & 2016 & Suudi Arabistan & Deneyim, farkındalık, güven, hoşlanmak \\
\hline Almarashdeh \& Alsmadi & 2017 & Suudi Arabistan & $\begin{array}{l}\text { Hizmet maliyeti, kullanışlılık, kullanım kolaylığı, sosyal etki, } \\
\text { teknolojiye güven }\end{array}$ \\
\hline Saxena & 2017 & Hindistan & Güven, kullanışl1lık, kullanım kolaylığı, tutum, öz yeterlilik \\
\hline Roubah et al. & 2018 & Kuveyt & $\begin{array}{l}\text { Ara yüz tasarımı, beklenti, bilgi kalitesi, değer algısı, } \\
\text { farkındalık, hizmet kalitesi, güven, tasarım, memnuniyet, risk ve } \\
\text { gizlilik algısı }\end{array}$ \\
\hline Ishengoma et al. & 2019 & Tanzanya & $\begin{array}{c}\text { Altyap1, erişim, güvenlik, kişisel faktörler, kullanılabilirlik, } \\
\text { maliyet }\end{array}$ \\
\hline
\end{tabular}

\section{MOBİL DEVLET KULLANIMINI ETKİLEYEN FAKTÖRLER VE HİPOTEZLER}

M-devlet kullanımını etkilediği düşünülen yedi faktöre yapılan literatür taraması sonucu ulaşılmıştır. Bu faktörler Bilgi Kalitesi (BK), Güvenlik Algısı (GG), Güven (GÜ), Hizmet Maliyeti (HM), Kullanım Kolaylığı (KK), Sosyal Etki (SE) ve Yararlılık (YA) şeklindedir. Aşağıda bu faktörler açıklanmış ve bu faktörler ile M-Devlet Kullanma Niyeti (KN) arasındaki çalışmanın hipotezleri sunulmuştur.

Bilgi kalitesi, m-devlette sunulan hizmetlerdeki bilgilerin doğruluğunu, eksiksizliğini ve güncelliğini göz önünde bulundurur. M-devlette sunulan bilgilerin doğru, doğrulanabilir, tam, ilgili ve zamanında olması kullanıcılar için önemli kriterlerdir. Dolayısıyla, aşağıdaki hipotez önerilmektedir:

H1: Bilgi kalitesi (KK) m-devlet kullanma niyetini (KN) doğrudan ve olumlu etkileyecektir.

Güvenlik ise kullanıcıların bilgilerinin izinsiz veya yetkisiz bir biçimde erişim, kullanım, değiştirilme, ortadan kaldırılma ve hasar verilmesini önlemek olarak tanımlanabilir. Gizlilik güvenliğin alt bileşenlerinden biri olup bilginin yetkisiz kişilerin eline geçmeme ve yetkisiz erişime karşı korunmasıdır (Çolak, 2020). Gizlilik ve güvenlik m-devletin uygulanması aşamasında karşılaşılan en önemli konulardır. Yapılan çalışmalarda da gizlilik ve güvenliğin başarılı m-devlet için ayırt edici özellikler 
olduğu vurgulanmıştır (Kushchu \& Kuscu, 2003; Sandy \& McMillan, 2005; Wang, 2014). Buna ilaveten güvenlik algısının yüksek olması m-devlet kullanımını olumlu yönde etkilediği çalışma sonuçlarında da görülmektedir (Shareef et al., 2012; Tan et al., 2012; Wang, 2014). Bu sonuçlara göre, aşağıdaki hipotez önerilmektedir:

H2: Güvenlik algısı (GG) m-devlet kullanma niyetini (KN) doğrudan ve olumlu etkileyecektir.

Diğer bir faktör güven olup bir tarafın beklentilerini karşılayacak şekilde karşı tarafın beklenen işlemi gerçekleştirmesi yönündeki öznel değerlendirmesidir. Bu nedenle güven, başkalarının gelecekteki davranışları hakkındaki belirsizliğin neden olduğu emin olamamayı içerirken karşı tarafın da kötü niyetli olmayacağına olan inancıdır (Colesca, 2009; Tan et al., 2012). Güven yapılan birçok e-devlet çalışmasında e-devlet kullanımını etkileyen faktörler arasında yer almaktadır (Khasawneh, Rabayah \& Abu-Shanab, 2013; Wang \& Lo, 2013; Rehman, Kamal \& Esichaikul; 2012; Bannister \& Connolly, 2011). Ayn1 doğrultuda m-devlet kullanımını da etkileyeceği açıktır. Bu doğrultuda aşağıdaki hipotez önerilmektedir:

H3: Güven (GÜ) m-devlet kullanma niyetini (BI) doğrudan ve olumlu etkileyecektir.

Hizmet maliyeti kullanıcıların m-devleti kullanma ve hizmet almak istemeleri sonucu karşılaştıkları maliyettir. Kullanıcılar m-devlet uygulamasını kullanabilmek için akıllı mobil cihaza, cihaz üzerinde uygulamayı indirebilmek için alana, kablolu ya da kablosuz internet bağlantısına ihtiyaç duymaktadırlar. Bu maliyet birimlerinin herhangi birisini tedarik edememe durumu m-devlet kullanma niyetleri olumsuz etkileyebilecektir. Dolayısıyla aşağıdaki hipotez önerilmektedir:

H4: Hizmet maliyeti (HM) m-devleti kullanma niyetini (BI) doğrudan ve olumsuz etkileyecektir.

Kullanım kolaylığı bir sistemin kullanımı esnasında kullanıcının minimum çaba ile başarabileceğine olan inancıdır. Teknolojiyi kullanmak kolay ise teknoloji önündeki engeller de kalkacaktır (Davis, 1989). Kullanım kolaylı̆̆ı inancının derecesi yükseldikçe kullanıcının sistemi kullanma niyeti de artacaktır. Çalışma sonuçlarında kullanım kolaylığının m- devlet kullanımını etkilediği belirtilmiştir (Shareef et al., 2012; Saxena, 2017). Bu nedenle aşağıdaki hipotez önerilmektedir:

H5: M-devletin kullanım kolaylığg (KK) m-devleti kullanma niyetini (BI) doğrudan ve olumlu etkileyecektir.

Sosyal etki kişilerin görüşlerini dikkate aldığı kişilerin düşünceleri sonucu davranışlarını değiştirmesidir. Başkaları tarafından kabul edilme ve beklentilerini karşılama arzusu sonucu kişiler m-devlet hizmetlerini kullanmaya başlamaktadırlar (AbuShanab \& Haider, 2015; Venkatesh \& Davis, 2000). Buna dayanarak aşağıdaki hipotez önerilmektedir:

H6: Sosyal etki (SE) m-devlet kullanma niyetini (BI) doğrudan ve olumlu etkileyecektir.

Yararlılık, kullanıcıların m-devlet uygulamasını kullanmaları durumunda sağlayacakları faydalardır. M-devleti kullanmak herhangi bir fayda ya da değer eklemediği zaman kullanıcılar m-devleti kullanmak istemeyeceklerdir. Buna dayanarak aşağıdaki hipotez önerilmektedir:

H7: Yararlılık (YA) m-devlet kullanma niyetini (BI) doğrudan ve olumlu etkileyecektir. Sonuç olarak çalışmada yukarıda açıklanan yedi tane hipotez bulunmaktadır.

\section{METODOLOJİ}

Bu çalışmada nicel araştırma yöntemi kullanılmıştır. Bu bölümde sırasıyla araştırmanın çalışma grubu, kuramsal modeli, veri toplama aracı, verilerin toplanması ve verilerin analizi sunulmuştur.

\section{1 Çalışma Grubu}

Araştırmaya katılacak üniversite öğrencileri seçilirken seçkisiz olmayan örnekleme yöntemlerinden uygun örnekleme yöntemi kullanılmıştır. Araştırmaya hız kazandırması ve erişilebilmesi kolay olan katılımcılara olanak sağladığı için bu yöntem tercih edilmiştir. Bu araştırmanın çalışma grubunu Ankara'da üç devlet üniversitesinde 2019-2020 öğretim yılı güz döneminde öğrenim gören 183 üniversite öğrencisi oluşturmaktadır. M-devlet kullanımı konusunda yapılan benzer çalışmalarda da Rana ve diğerleri (2019) 81, Abdelghaffer ve Magdy 100, Abaza ve Saif (2015) 120 ve Almarashdeh ve Alsmadi (2017) 468 katılımcı sayıları ile çalışmalarını gerçekleştirmişlerdir. Bu nedenle bu araştırmanın çalışma grubunun sayısının yeterli olduğu düşünülmüştür. Ayrıca öğrencilerin mutlaka m-devleti kullanıyor olmalarına dikkat edilmiştir. Üniversite öğrencilerinin 
seçilmiş olmasının sebebi Türkiye İstatistik Kurumu 2019 yılı Hanehalkı Bilişim Teknolojileri Kullanım Araştırmasına göre 18-24 yaş grubunun bilgisayar ve interneti en yoğun $(\% 90,8)$ olarak kullanan yaş aralığı olmasıdır (Bayrak, 2020). Öğrenciler Endüstri ve Makine Mühendisliği, Fen Bilgisi Öğretmenliği ve Yönetim Bilişim Sistemleri bölümleri öğrencileri olup, araştırmaya gönüllü olarak katılmışlardır. Tablo 2'de araştırmaya katılan çalışma grubunun demografik özellikleri görülmektedir.

Tablo 2 incelendiğinde katılımcıların büyük çoğunluğunun (\%94) 18-24 yaş aralığında olduğu görülmektedir. Buna ilaveten katılımcıların \%65’i 3. ve 4.sınıf öğrencileridir. Buna ilaveten mühendislik ve yönetim bilişim sistemleri öğrencilerinin çoğunlukta (\%60) olması bu öğrencilerin teknolojik gelişmelere ve bilişim teknolojilerine daha ilgili olmalarından dolayı araştırma için avantaj olarak değerlendirilebilir.

Tablo 2

Çalışma grubunun demografik özellikleri

\begin{tabular}{|c|c|c|}
\hline Cinsiyet & Sayı & $\%$ \\
\hline Kadın & 109 & 59 \\
\hline Erkek & 74 & 41 \\
\hline Yaş & Sayı & $\%$ \\
\hline $18-20$ & 40 & 22 \\
\hline $21-23$ & 130 & 71 \\
\hline $24-27$ & 13 & 7 \\
\hline Sinıf & Sayı & $\%$ \\
\hline 1.Sinif & 22 & 12 \\
\hline 2.Sinif & 41 & 22 \\
\hline 3.Sinif & 46 & 25 \\
\hline 4.Sinif & 74 & 41 \\
\hline Bölüm & Sayı & $\%$ \\
\hline Makine Mühendisliği & 11 & 6 \\
\hline Endüstri Mühendisliği & 26 & 14 \\
\hline Fen Bilgisi Öğretmenliği & 73 & 40 \\
\hline Yönetim Bilişim Sistemleri & 73 & 40 \\
\hline
\end{tabular}

\subsection{Araştırmanın Kuramsal Modeli}

Kuramsal modeli geliştirebilmek için ilk olarak literatür taraması yapılmıştır. Yapılan tarama sonucunda m-devlet kullanımını etkilediği düşünülen faktörler tespit edilmiştir. M-devlet kullanımını etkilediği düşünülen faktörler: bilgi kalitesi, güvenlik algısı, güven, hizmet maliyeti, kullanım kolaylığı, sosyal etki, yararlılıktır. Kuramsal modelde yedi tane faktör gözlenemeyen gizil değişkenler olup bir tane bağımlı gözlenemeyen değişken (m-devleti kullanma niyeti) bulunmaktadır. Bu çalışmadaki yedi faktör gizil değişkenler olup bu değişkenler ile m-devlet kullanımı arasındaki nedensel ilişkiler açıklanmaya çalışılmıştır. $\mathrm{Bu}$ gizil değişkenler arasındaki ilişkiler ve hipotezler Şekil 1'de sunulmuştur.

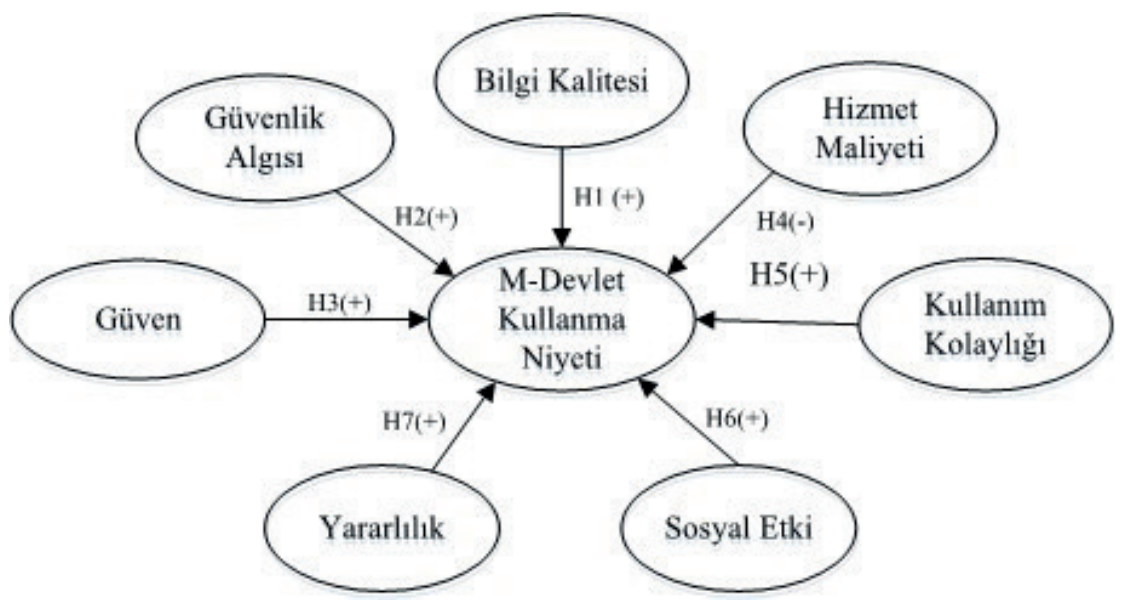

Şekil 1. Kuramsal model ve hipotezler 


\subsection{Veri Toplama Aracı}

M-devlet kullanımını etkileyen faktörleri belirlemek için bir ölçek hazırlanmıştır. Hazırlanan ölçekteki maddelerin belirlenmesi için kapsamlı bir literatür taraması yapılarak farklı ülkelerin m-devlet kullanımını etkileyen faktörlerin araştırıldığı araştırma makaleleri incelenmiştir. Ölçekte yer alması uygun görülen maddeler için araştırmacılarla elektronik posta aracılıyla iletişime geçilmiş ve gerekli izinler alınmıştır. Bu çalışmalar İngilizce olduğundan ölçek maddelerinin Türkçeye çevrilmesi süreci üç aşamada gerçekleştirilmiştir. Birinci aşamada dilsel eş değerliliği sağlamak için ölçek maddelerini Türkçeye çevirecek kişiler belirlenmiştir. Çeviri işleminde üç kişi bulunmaktadır. İki kişi yüksek lisans ve doktorasını yurt dışında tamamlamış iki öğretim üyesi olup üçüncü kişi İngilizce eğitim verilen bir üniversitedeki öğretim üyesidir. Üç kişi ölçek maddelerini çevirdikten sonra bir araya getirilerek gerekli uyumlaştırma çalışmaları yapılarak düzeltmeler yapılmıştır. İkinci aşamada Türk Dili ve Edebiyatı bölümü öğretim üyesi tarafından dil bilgisi kuralları ve anlaşılabilirliği dikkate alınarak değerlendirilmiştir. Öneriler doğrultusunda gerekli düzeltmeler yapılmıştır. Üçüncü aşama da on üniversite öğrencisi ile ölçek maddeleri tartışılmış ve ölçek maddelerinin son haline ulaşılmıştır. Veri toplama aracı olarak 30 maddeden oluşan M-Devlet Kullanımı Ölçeği (M-DKÖ) geliştirilmiştir. Tablo 3'de ölçme aracındaki faktörler, madde sayıları ve maddelerin derlendiği kaynaklar görülmektedir. Ölçekte 5'li Likert ölçeği kullanılmış ve 1-5 şeklinde (1. Kesinlikle katılmıyorum 5. Kesinlikle katılıyorum) ölçeklendirilmiştir. Tablo 4'te ölçek maddeleri görülmektedir.

Tablo 3

Ölçme aracındaki faktörler ve madde sayıları

\begin{tabular}{lcc}
\hline Faktör adı & Madde sayısı & Kaynaklar \\
\hline Bilgi kalitesi & 5 & Abu-Shanab \& Haider, 2015; Colesca, 2009 \\
Güvenlik algısı & 4 & Colesca, 2009 \\
Güven & 4 & Almarashdeh \& Alsmadi, 2017 \\
Hizmet kalitesi & 3 & Almarashdeh \& Alsmadi, 2017; Saxena, 2017 \\
Kullanım kolaylığ 1 & 4 & Colesca, 2009; Saxena, 2017 \\
Sosyal etki & 3 & Abu-Shanab \& Haider, 2015; Saxena, 2017 \\
Yararlılık & 4 & Almarashdeh \& Alsmadi, 2017 \\
M-devlet kullanma niyeti & 3 & Almarashdeh \& Alsmadi, 2017; Saxena, 2017 \\
\hline
\end{tabular}

Tablo 4

M-Devlet kullanımı ölçeği maddeleri

\begin{tabular}{|c|c|c|}
\hline \multirow{4}{*}{ 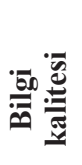 } & 1 & M-devlet hizmetler hakkında kapsamlı bilgiler sunmaktadır. \\
\hline & 2 & M-devlet hizmetler hakkında doğru bilgiler sunmaktadır. \\
\hline & 3 & M-devlet uygulamasındaki bilgiler günceldir. \\
\hline & 4 & M-devletin kullanımı şeffaflık düzeyini artırmaktadır. \\
\hline \multirow{4}{*}{ 莺 } & 5 & M-devletin kullanımı vatandaşlar arasında bilgiye ulaşım konusunda fırsat eşitliği sağlamaktadır. \\
\hline & 6 & M-devlet hizmetlerini kullanmak için gerekli akıllı telefon ve benzeri mobil cihazların pahalı olduğunu düşünüyorum. \\
\hline & 7 & M-devlet hizmetlerine erişimin pahalı olduğunu düşünüyorum. \\
\hline & 8 & M-devlet hizmetleri işlem maliyetinin pahalı olduğunu düşünüyorum. \\
\hline \multirow{4}{*}{ 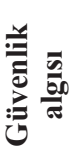 } & 9 & M-devlet gizliliğimi korumaktadır. \\
\hline & 10 & M-devlet uygulamasında kişisel bilgilerim korunmaktadır. \\
\hline & 11 & M-devlet sisteminde kişisel bilgilerime benim dişımda kimse ulaşamaz. \\
\hline & 12 & M-devlet sistemi siber saldırılara karşı korunmaktadır. \\
\hline \multirow{4}{*}{ : } & 13 & Devletin mobil hizmetleri güvenli bir şekilde sunacağına inanıyorum. \\
\hline & 14 & M-devletin internet altyapısına güveniyorum. \\
\hline & 15 & M-devlet hizmeti alırken kullandığım mobil cihaza güveniyorum. \\
\hline & 16 & M-devlet hizmeti veren kamu kurumlarına güveniyorum. \\
\hline \multirow{3}{*}{ 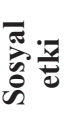 } & 17 & Karar verme süreçlerinde görüşlerini dikkate aldığım kişiler m-devleti kullanmam gerektiğini düşünüyor. \\
\hline & 18 & Çevremdeki önem verdiğim insanlar, m-devleti kullanabileceğimi düşünüyor. \\
\hline & 19 & Çevremdeki önem verdiğim kişiler, m-devleti kullanmamın faydalı olacağını düşünüyor. \\
\hline
\end{tabular}




\begin{tabular}{|c|c|c|}
\hline \multirow{4}{*}{ 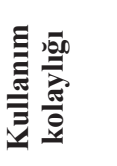 } & 20 & M-devlet hizmetlerinin sunulduğu uygulamaların kullanımı kolaydır. \\
\hline & 21 & M-devlette sunulan yeni bir hizmet uygulamasının kullanımını öğrenmek benim için kolaydır. \\
\hline & 22 & M-devlette sunulan hizmetler açık ve anlaşılırdır. \\
\hline & 23 & M-devlette ihtiyaç duyduğum her hizmeti almak benim için kolaylık olurdu. \\
\hline \multirow{4}{*}{ 㭉 } & 24 & M-devlet uygulamasındaki hizmetleri kullanmak, işlerimi daha hızlı yapmama yardımcı oluyor. \\
\hline & 25 & M-devlet uygulamasındaki hizmetleri alabilmek hayatımı kolaylaştırıyor. \\
\hline & 26 & M-devlet uygulamasındaki hizmetleri günlük yaşamım için faydalı buluyorum. \\
\hline & 27 & M-devlet uygulamasındaki hizmetleri kullanmak verimliliğimi artırıyor. \\
\hline \multirow{3}{*}{ 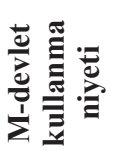 } & 28 & İhtiyacım olduğunda m-devlet kullanmayı düşünüyorum. \\
\hline & 29 & Hizmet almak için m-devlet uygulamalarını sık sık kullanmayı düşünüyorum. \\
\hline & 30 & Firsat verildiğinde m-devlet kullanmayı düşünüyorum. \\
\hline
\end{tabular}

\subsection{Verilerin Toplanması}

Verileri toplama sürecine başlamadan önce Ankara Yıldırım Beyazıt Üniversitesi Sosyal ve Beşeri Bilimler Etik Kurulu’ndan (27.12.2019 tarih ve 53 karar no) onay alınmıştır. Onaydan sonra verilerin toplanması Ocak 2020 yılında Ankara’daki üç devlet üniversitesinde gerçekleştirilmiştir. Veri toplama süreci araştırmacı tarafından gerçekleştirilmiştir.

\subsection{Verilerin Analizi}

M-devlet kullanımını etkileyen faktörlerin belirlenmesi için hazırlanan ölçeğinin faktör yapısı LISREL 8.72 paket programı kullanılarak analiz edilmiştir. Ölçeğin geçerlik çalışmaları doğrulayıcı faktör analizi (DFA) ile gerçekleştirilmiştir. Şekil 1'deki kuramsal model Yapısal Eşitlik Modeli (YEM) yöntemiyle analiz edilmiştir. Verilerin analizi sonuçlarında maddelerin t değerleri, hata varyansları ve standart yükleri kontrol edilmiştir. Kuramsal modelin gerçek verilerle uyumunu değerlendirmek için Yaklaşık Hataların Ortalama Karekökü (Root Mean Square Error of Approximation, RMSEA), Normlandırılmış uyum indeksi (The Normed Fit Index, NFI), Normlandırılmamış uyum indeksi (The Non-Normed Fit Index, NNFI), Karşılaştırmalı uyum indeksi (Comparative Fit Index, CFI), Karşılaştırmalı Uyum İndeksi (Comparative Fit Index, CFI), Uyum iyiliği indeksi (Goodness-of-fit index, GFI) ve Düzeltilmiş İyilik Uyum İndeksleri (Adjusted Goodness of Fit Index, AGFI) olmak üzere altı uyum indeksi değeri kontrol edilmiştir (Cole \& Maxwell, 2003). Buna ilaveten ki-kare ( $\chi 2$ ) değeri örneklem büyüklügünden etkilendiği ve geniş örneklemlerde olumlu sonuç verdiği için analizlerde ki-karenin serbestlik derecesine ( $\chi 2$ /sd) oranına bakılmıştır (Tabachnick, Fidell \& Osterlind, 2007:506).

\section{BULGULAR}

Bu bölümde sırasıyla ölçeğin güvenirlik ve geçerlik ile kuramsal modelin test edildiği YEM yöntemi analiz sonuçları sunulmuştur.

Ölçeğin güvenirliği için güvenirlik katsayısı hesaplama tekniklerinden iç tutarlılık yöntemi seçilmiştir. Bunun içinden de Cronbach alfa iç güvenirlik katsayısı yöntemi kullanılmıştır. Ölçek için hesaplanan Cronbach alfa iç güvenirlik katsayısı $(\alpha=0,89)$ 0,89 olup bu değer ölçeğin yüksek derecede güvenilir olduğunu göstermektedir. Her faktöre ait Cronbach alfa iç güvenirlik katsayıları ise; bilgi kalitesi için 0,88 , güvenlik algısı ve güven için 0,83 , sosyal etki için 0,87 , kullanım kolaylığ için 0,84, hizmet maliyeti ve yararlılık için 0,73’tür. Bilgi kalitesi, güvenlik algısı, güven, sosyal etki, kullanım kolaylığ faktörleri yüksek derece güvenilir olup hizmet maliyeti ve yararlılık faktörleri ise oldukça güvenilirdir.

Verilerin analizi için YEM uygulanmış ve DFA LISREL 8.72 bilgisayar programında gerçekleştirilmiştir. Verilerin hazırlanması süreci üç adımda gerçekleştirilmiştir. Birinci adımda veriler tanımlanmıştır. İkinci adımda DFA için kovaryans matrisi oluşturulmuştur. Üçüncü adımda da gerçekleştirilecek her bir analiz için sözdizimleri LISREL programında yazılarak verilerin analizi süreci başlatılmıştır.

Şekil 1'de görüldüğü gibi bu çalışmanın kuramsal modelinde sekiz ölçme modeli bulunmaktadır. İlk olarak her ölçme modelinin faktör yapısı DFA ile test edilmiştir. Yapılan analizleri değerlendirmek için ilk olarak t değerleri kontrol edilmiştir. Her ölçme modelindeki maddelerin tümünün t değerinin 2,56'dan büyük olduğu için 0,01 düzeyinde istatistiksel olarak 
anlamlı olduğu sonucuna varılmıştır (Çokluk, Şekercioğlu \& Büyüköztürk, 2010:223; Nunnally, 1994). İkinci olarak hata varyanslarına bakılmış ve hata varyanslarının da düşük (<90) olduğu görülmüştür. Son olarak her bir ölçme modelinin doğrulanıp doğrulanmadığını test etmek için uyum indeksleri ( $\chi 2$ /sd, RMSEA, NFI, NNFI, CFI, GFI, AGFI) değerlendirilmiş̧ir. Değerlendirmeler sonucunda kuramsal modelde bulunan sekiz ölçme modeli doğrulanmıştır. Daha sonra Şekil l'de görülen kuramsal modele DFA uygulanmıştır. Tablo 5’te kuramsal modelin DFA sonuçları görülmektedir.

Tablo 5 incelendiğinde tüm maddelerin hata varyanslarının 0,23 ile 0,66 arasında değiştiği görülmektedir. Bu durum yüksek hata varyansının olmadığı şeklinde yorumlanıp istenen bir durumdur. Diğer incelenmesi gereken değer maddelerin path katsayıları (standartlaştırılmış faktör yükleri) olup 0,64 ile 0,88 arasında değişmektedir ve bu path katsayıları parametrik sınamada $t$ değerlerine göre istatistiksel olarak anlamlı bulunmuştur. Diğer taraftan Tablo da görüldüğü gibi altı madde (BK1, GG1, GU1, SE1, KK1 ve YA1) için t değeri hesaplanmamıştır. Buna rağmen düşük hata varyansları ve yüksek path katsayılarına sahip oldukları için ölçme modelinden çıkarılmamışlardır.

Tablo 5'te görüldüğü gibi her bir faktörün yapı güvenirliği hesaplanmıştır. Her bir faktör için yapı güvenirliği 0,70'den büyük olduğundan bu değerler ölçme sonuçlarının güvenilir olduğunu göstermektedir (Nunnally, 1994). Buna ilaveten yakınsama geçerliği için faktör yükleri ve ortalama açıklanan varyans (OAV) değerleri incelenmiştir. Faktör yüklerinin ve OAV değerlerinin hepsinin 0,50'den büyük olması yakınsama geçerliliğinin sağlandığını göstermektedir (Fornell \& Larcker, 1981). Ayrıca yapısal güvenirlik değerlerinin her biri de OAV değerlerinden büyüktür ve bu durum da yakınsama geçerliliğinin bir diğer kanıtı olarak gösterilebilir.

Fornel ve Larcker (1981), ayırt edici geçerlik için kuramsal modelin faktörleri arasındaki korelasyonlardan ve OAV değerlerinin karekökünden yararlanılması gerektiğini belirtmişlerdir. Herhangi boyuttaki OAV’ın karekökünün o faktörün diğer faktör ile aralarındaki korelasyondan ve aynı zamanda 0,50 değerinden küçük olmaması gerektiğini vurgulamışlardır. Kuramsal modelin faktörleri arasındaki korelasyonlar ve OAV değerlerinin karekök değerleri Tablo 6'da görülmektedir.

Tablo 5

Kuramsal modelin DFA sonuçları

\begin{tabular}{|c|c|c|c|c|c|c|}
\hline Maddeler & $\begin{array}{c}\text { Hata } \\
\text { Varyansları }\end{array}$ & Path Katsayıları & t Değerleri ${ }^{1}$ & Yapı Güvenirliği & $\begin{array}{c}\text { Ortalama Açıklanan } \\
\text { Varyans }\end{array}$ & $\mathbf{R}^{2}$ \\
\hline \multicolumn{7}{|l|}{ Bilgi Kalitesi } \\
\hline BK1 & 0,24 & 0,84 & - & \multirow{5}{*}{0,80} & \multirow{5}{*}{0,56} & 0,71 \\
\hline BK2 & 0,23 & 0,88 & $14,57 * *$ & & & 0,77 \\
\hline BK3 & 0,33 & 0,82 & $13,14^{* *}$ & & & 0,67 \\
\hline BK4 & 0,54 & 0,69 & $10,26^{* *}$ & & & 0,47 \\
\hline BK5 & 0,49 & 0,71 & $10,83 * *$ & & & 0,51 \\
\hline \multicolumn{7}{|l|}{ Hizmet Maliyeti } \\
\hline HM1 & 0,62 & 0,61 & $3,46 * *$ & \multirow{3}{*}{0,82} & \multirow{3}{*}{0,60} & 0,38 \\
\hline HM 2 & 0,26 & 0,86 & $7,98 * *$ & & & 0,74 \\
\hline HM 3 & 0,30 & 0,83 & $8,06^{* *}$ & & & 0,70 \\
\hline \multicolumn{7}{|l|}{ Güvenlik Alg1sı } \\
\hline GG1 & 0,24 & 0,87 & - & \multirow{4}{*}{0,83} & \multirow{4}{*}{0,56} & 0,76 \\
\hline GG2 & 0,23 & 0,87 & $13,49 * *$ & & & 0,75 \\
\hline GG3 & 0,33 & 0,63 & $9,07 * *$ & & & 0,40 \\
\hline GG4 & 0,66 & 0,54 & $8,25 * *$ & & & 0,34 \\
\hline \multicolumn{7}{|l|}{ Güven } \\
\hline GU1 & 0,46 & 0,74 & - & \multirow{4}{*}{0,91} & \multirow{4}{*}{0,58} & 0,54 \\
\hline GU2 & 0,29 & 0,84 & $10,78^{* *}$ & & & 0,71 \\
\hline GU3 & 0,59 & 0,64 & $8,20 * *$ & & & 0,41 \\
\hline GU4 & 0,36 & 0,80 & $10,31 * *$ & & & 0,64 \\
\hline
\end{tabular}




\begin{tabular}{|c|c|c|c|c|c|c|}
\hline \multicolumn{7}{|l|}{ Sosyal Etki } \\
\hline SE1 & 0,27 & 0,85 & - & \multirow{3}{*}{0,90} & \multirow{3}{*}{0,70} & 0,73 \\
\hline SE2 & 0,32 & 0,83 & $12,85^{* *}$ & & & 0,68 \\
\hline SE3 & 0,31 & 0,83 & $12,99 * *$ & & & 0,69 \\
\hline \multicolumn{7}{|c|}{ Kullanım Kolaylığ1 } \\
\hline KK1 & 0,25 & 0,86 & - & \multirow{4}{*}{0,86} & \multirow{4}{*}{0,61} & 0,75 \\
\hline KK2 & 0,39 & 0,78 & $12,54 * *$ & & & 0,61 \\
\hline KK3 & 0,46 & 0,73 & $11,38 * *$ & & & 0,54 \\
\hline KK4 & 0,45 & 0,74 & $11,62 * *$ & & & 0,55 \\
\hline \multicolumn{7}{|l|}{ Yararlılık } \\
\hline YA1 & 0,36 & 0,80 & - & \multirow{4}{*}{0,89} & \multirow{4}{*}{0,68} & 0,64 \\
\hline YA2 & 0,24 & 0,87 & $13,48^{* *}$ & & & 0,76 \\
\hline YA3 & 0,28 & 0,85 & $12,99 * *$ & & & 0,72 \\
\hline YA4 & 0,40 & 0,78 & $11,55^{* *}$ & & & 0,60 \\
\hline \multicolumn{7}{|c|}{ M-Devlet Kullanma Niyeti } \\
\hline KN1 & 0,36 & 0,80 & $12,72 * *$ & \multirow{3}{*}{0,84} & \multirow{3}{*}{0,64} & 0,64 \\
\hline KN2 & 0,37 & 0,79 & $12,66^{* *}$ & & & 0,63 \\
\hline \multirow[t]{2}{*}{ KN3 } & 0,34 & 0,81 & $13,05^{* *}$ & & & 0,66 \\
\hline & \multicolumn{2}{|c|}{ Standartlaştırılmış katsayılar (beta) } & $\mathrm{t}$ değer & \multicolumn{3}{|c|}{$\mathrm{R}^{2}$ değerleri } \\
\hline $\mathrm{BK} \rightarrow \mathrm{KN}$ & 0,69 & & $8,93 *$ & \multicolumn{3}{|c|}{0,48} \\
\hline $\mathrm{HM} \rightarrow \mathrm{KN}$ & $-0,14$ & & $-1,70$ & \multicolumn{3}{|c|}{0,02} \\
\hline $\mathrm{GG} \rightarrow \mathrm{KN}$ & 0,62 & & $7,93^{*}$ & \multicolumn{3}{|c|}{0,38} \\
\hline $\mathrm{GU} \rightarrow \mathrm{KN}$ & 0,80 & & $6,95^{\circ}$ & \multicolumn{3}{|c|}{0,64} \\
\hline $\mathrm{SE} \rightarrow \mathrm{KN}$ & 0,71 & & $9,18^{*}$ & \multicolumn{3}{|c|}{0,51} \\
\hline $\mathrm{KK} \rightarrow \mathrm{KN}$ & 0,89 & & 12,18 & \multicolumn{3}{|c|}{0,79} \\
\hline $\mathrm{YA} \rightarrow \mathrm{KN}$ & 0,90 & & $11,31^{*}$ & \multicolumn{3}{|c|}{0,81} \\
\hline
\end{tabular}

Tablo 6

Faktörler arasındaki korelasyon ve OAV değerlerinin karekökü

\begin{tabular}{|c|c|c|c|c|c|c|c|c|}
\hline Faktörler & Sembol & [1] & [2] & [3] & [4] & [5] & [6] & [7] \\
\hline Bilgi Kalitesi & [1] & 0,75 & & & & & & \\
\hline Hizmet Maliyeti & [2] & $-0,10$ & 0,78 & & & & & \\
\hline Güvenlik Algisı & [3] & 0,43 & $-0,09$ & 0,75 & & & & \\
\hline Güven & [4] & 0,55 & $-0,11$ & 0,49 & 0,76 & & & \\
\hline Sosyal Etki & [5] & 0,49 & $-0,10$ & 0,44 & 0,57 & 0,84 & & \\
\hline Kullanım Kolaylığı & [6] & 0,61 & $-0,13$ & 0,55 & 0,71 & 0,63 & 0,78 & \\
\hline Yararlılık & [7] & 0,62 & $-0,13$ & 0,56 & 0,72 & 0,64 & 0,78 & $\mathbf{0 , 8 0}$ \\
\hline
\end{tabular}

Tablo 6 incelendiğinde korelasyon matrisinin köşegen elemanları OAV’ın karekökünü (koyu olan değerler) ve köşegen dışı elemanlar ise boyutlar arasındaki korelasyon değerlerini göstermektedir. Tablo 6'da görüldüğü gibi her bir boyuttan hesaplanan OAV değerlerinin karekökü diğer alt faktörler ile olan korelasyon değerlerinden daha büyüktür. Örneğin sosyal etki faktörünün OAV karekökü 0,84 olup bu faktörün diğer faktörlerle olan korelasyonundan daha büyük olduğu görülmektedir. Bu durum diğer tüm boyutlar için de geçerli olup sadece kullanım kolaylığı faktörünün OAV değerinin karekökü ile yararlılık arasındaki korelasyon değeri eşittir. Bu sonuçlar doğrultusunda ölçeğin ayırt edicilik geçerliği sağladığı söylenebilir.

Kuramsal model için hesaplanan uyum iyiliği istatistikleri de Tablo 7'de görülmektedir. Kuramsal model için Tablo 7'deki uyum ölçütleri incelendiğinde RMSEA indeksi sadece zayıf uyum gösterirken, CFI, GFI ve AGFI kabul edilebilir uyum, $\mathrm{X}^{2} / \mathrm{d}$, NFI ile NNFI iyi uyum göstermektedir. Sonuç olarak modelin kabul edilebilir uyum gösterdiği söylenebilir. 
Tablo 7

Kuramsal modelin uyum ölçüleri

\begin{tabular}{lcc}
\hline Uyum Ölçüsü & Değeri & Uyum \\
\hline $\mathrm{X}^{2} /(\mathrm{d}=398)$ & 2,7 & İyi uyum \\
RMSEA & 0,09 & Zayıf uyum \\
NFI & 0,92 & İyi uyum \\
NNFI & 0,94 & Iyi uyum \\
CFI & 0,91 & Kabul edilebilir uyum \\
GFI & 0,87 & Kabul edilebilir uyum \\
AGFI & 0,85 & Kabul edilebilir uyum \\
\hline
\end{tabular}

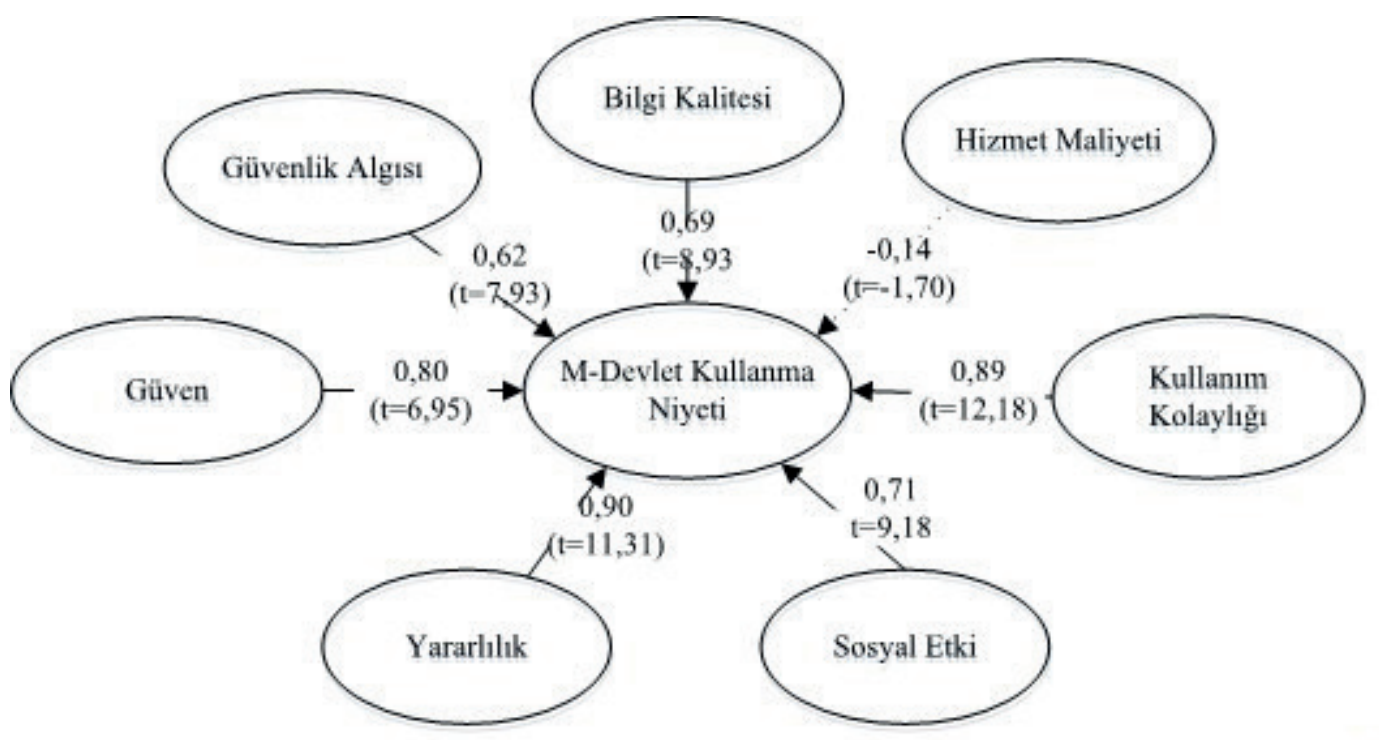

Şekil 2. Araştırma modeli ve DFA sonuçları

Şekil 2'de kuramsal modelde yer alan bağımlı gizil değişken ve bağımsız gizil değişkenler arasındaki nedensel ilişkiler görülmektedir. Şekil 2 incelendiğinde BK ile KN arasındaki katsayının 0,69'dur. Öğrenciler için bilgi kalitesi önemli olup bilgi kalitesi arttığında m-devlet kullanma niyetlerinde de artış olacağı yönünde yorumlanabilir. Sonuç olarak H1 hipotezi desteklenmiştir. Diğger bir faktör olan GG ile KN arasındaki katsayı 0,62'dir. Öğrencilerin güvenlik algısı olumlu arttığında m-devlet kullanma niyetleri artacak olup bu durumu ifade eden $\mathrm{H} 2$ hipotezi de desteklenmiştir. Çalışmanın $\mathrm{H} 3$ hipotezi GU ile KN arasında olup aralarındaki katsayı değeri 0,80'dir. Bu değer öğrencilerin güvenlerinin artması durumunda m-devlet kullanma niyetlerinin de artacağı şeklinde yorumlanabilir. H3 hipotezi de istatistiksel olarak desteklenmiştir. Diğer taraftan HM ile KN arasındaki katsayı -0,14 olup manidar t değeri de (-1,70) vermediğinden dolayı H4 hipotezi desteklenememiştir. KK ile KN arasındaki ilişki katsayısı 0,89 olduğu Şekil 2'de görülmektedir. KK'daki bir puanlık artış KN'de 0,89 puanlık yükselişe neden olacak olup H5 hipotezi de desteklenmiştir. Çalışmanın altıncı hipotezi SE ile KN arasındadır. Bu iki değer arasındaki ilişki katsayısı 0,71 olup H6 hipotezi de desteklenmiştir. En yüksek ilişki katsayısının 0,90 ile YA ile KN arasında olduğu görülmektedir. Bu değer, öğrencilerin m-devleti kullanmalarının yararlı olduğunu düşündüklerinde kullanmalarının artacağını göstermektedir. YA'daki bir puanlık artış KN'de 0,90 puanlık yüksek bir artışa neden olacaktır. Bu ilişkinin ifade edildiği H7 hipotezi de istatistiksel olarak desteklenmiştir.

Sonuç olarak H1, H2, H3, H5, H6 ve H7 hipotezleri desteklenirken H4 hipotezi desteklenememiştir.

\section{SONUC VE ÖNERILLER}

$\mathrm{Bu}$ çalışmada üniversite öğrencilerinin m-devlet kullanımını etkileyen faktörler araştırılmıştır. Çalışmanın verileri Ankara'daki üç devlet üniversitesindeki öğrencilerden toplanmıştır. Verilere uygulanan DFA sonucu kavramsal modelde önerilen yedi faktörden (bilgi kalitesi, güvenlik algısı, güven, hizmet maliyeti, kullanım kolaylığı, sosyal etki, yararlılık) sadece biri hariç 
(hizmet maliyeti) diğer altısının m-devlet kullanımını etkilediği görülmüştür. Çalışma sonuçlarına göre faktörlerin m-devleti kullanma niyetine etkisine göre büyükten küçüğe şöyle sıralanmaktadır: Yararlılık, kullanım kolaylığı, güven, sosyal etki, güvenlik algısı, bilgi kalitesidir. Bu çalışmanın belirleme katsayısı $\left(\mathrm{R}^{2}\right) \% 69,4$ olup bu altı faktör birlikte m-devlet kullanımını etkileyen faktörlerin \%69,4’ünü açıklamaktadır.

Çalışma sonuçları literatür ile paralellik göstermektedir. İlk üç sırada m-devlet kullanımını etkilediği görülen faktörler yararlılık, kullanım kolaylığı ve güvendir. Mobil Hizmet Kabul Modeli’ne göre de yararlılık, kullanım kolaylığı ve güven mobil hizmeti kullanma niyetini direk etkilemektedir (Gao, Krogstie \& Gransæther, 2008). Bir diğer çalışma sonucunda da bu üç faktöre ilaveten erişim, altyapı ve kullanılabilirlik de m-devlet kullanmayı etkileyen faktörler olarak rapor edilmiştir (Ishengoma et al., 2019). Farklı ülkelerde yapılan araştırma sonuçlarının büyük çoğunluğunda da bu üç faktörün etkili olduğu Tablo 1'de görülmektedir.

Çocukların ve gençlerin çevrelerindeki kişilerden etkilenmeleri ve davranışlarını bu doğrultuda düzenlemeleri sıklıkla rastlanılan bir durumdur. Bu çalışma sonucunda da üniversite öğrencilerinin çevrelerindeki insanların m-devlet kullanımında etkili olduğu görülmüştür. Literatürde bulunan teknoloji ya da hizmet kabul modelleri (TAM2, UTAUT, TPB) içerisinde de sosyal etkinin bulunduğu görülmektedir (Davis, 1989; Venkatesh \& Davis, 2000; Venkatesh et al., 2003). Buna ilaveten Almarashdeh ve Alsmadi tarafından 2016 yılında yapılan ve kullanıcıların m-devleti benimseme ve kullanma faktörlerini araştıran çalışma sonucunda da en fazla etkili olan faktör sosyal etki olarak rapor edilmiştir.

Güvenlik algısının olumlu yönde olması da m-devlet kullanımını olumlu etkilemektedir. Güvenlik algısının m-devlet kullanımını etkileyen faktörler arasında beşinci sırada olması dikkat çekicidir. Bu durum günümüzde bilişim sistemlerinin güvenliğinin sağlanması kullanıcılar tarafından bir zorunluluk olarak görüldüğü şeklinde yorumlanabilir. Literatürle (Alkhamayseh et al., 2006; Roubah, et al., 2018) paralellik gösteren bu sonuç aynı zamanda kullanıcıların Türkiye'de m-devlet ile güvenli bağlantılar kurdukları algısına sahip olduklarını da göstermektedir. Üniversite öğrencilerinin güvenlik algılarının olumlu olması m-devlet için bir başarı olup geleceğini de olumlu etkileyecektir.

Bilgi kalitesi m-devlet kullanımını etkileyen bir diğer faktör olup yapılan çalışmalarda da bilişim sistemleri, e-devlet ve m- devlet kullanıcı niyetini etkilediği rapor edilmiştir (Koivumaki, Ristola \& Kesti, 2008; Veeramootoo, Nunkoo \& Dwivedi, 2018; Wang, 2008).

Bu araştırmanın bulgularına göre hizmet maliyeti faktörü m-devlet kullanımını etkilememektedir. Bu sonuç değerlendirildiğinde öğrencilerin m-devlet hizmetine erişimi, erişebilecekleri cihazı ve işlem maliyetini kolaylıkla karşılayabildikleri söylenebilir. Literatürde yer alan araştırma sonuçları değerlendirildiğinde bazı çalışma sonuçlarında hizmet maliyetinin m-devlet kullanımını etkilediği görülürken (Al-Hadidi \& Rezgui, 2010; Al-khamayseh et al., 2006; Ishengoma et al., 2019) bazıları da etkilemediğini belirtmektedir. (Abu-Shanab \& Haider, 2015; El-Kiki \& Lawrence, 2006; Hung et al., 2013; Rana et al., 2019). Sonuç olarak çalışmanın bulguları etkili ve etkin bir m-devlet sistemi kurmaktan sorumlu olan birimler için yol gösterici olacaktır. Başarılı bir m-devlet uygulamasına tüm paydaşların katkılarıyla ulaşılabileceği unutulmamalıdır. Bu doğrultuda en önemli paydaş olan kullanıcıların m-devleti kullanmalarını etkileyen faktörlerin bilinmesi ve bu doğrultuda çalışmaların yapılması kritik öneme sahiptir.

Her çalışmanın olduğu gibi bu çalışmanın da bazı sınırlıkları bulunmaktadır. Çalışma Ankara ilinde ve devlet üniversitelerinde gerçekleştirilmiş nicel bir araştırmadır. Gelecekte buna benzer çalışmaların kapsamı yüksek lisans öğrencileri ile özel üniversitelerde okuyan üniversitelerde okuyan öğrencilerle görüşmeler yapılarak genişletilebilir. Bu çalışmada m-devlet kullanımını etkileyen yedi temel faktör değerlendirilmiş̧ir. Ayrıca m-devlet kullanımını etkileyebilecek muhtemel aracı değişkenler araştırılarak sunulan modele eklenebilir. 
Hakem Değerlendirmesi: Dış bağımsız.

Çıkar Çatışması: Yazar çıkar çatışması bildirmemiştir.

Finansal Destek: Yazar bu çalışma için finansal destek almadığını beyan etmiştir.

Peer-review: Externally peer-reviewed.

Conflict of Interest: The author has no conflict of interest to declare.

Grant Support: The author declared that this study has received no financial support.

\section{Kaynaklar/References}

Abaza, M., \& Saif, F. (2015). The adoption of mobile government services in developing countries. IJCSI International Journal of Computer Science Issues, 12(1), 137-145.

Abdelghaffar, H., \& Magdy, Y. (2012). The adoption of mobile government services in developing countries: The case of Egypt. International Journal of Information and Communication Technology Research, 2(4), 333-341.

Abu-Shanab, E., \& Haider, S. (2015). Major factors influencing the adoption of m-government in Jordan. Electronic Government an International Journal, 11(4), 223-240.

Al-Hadidi, A., \& Y. Rezgui, Y. (2010). Adoption and diffusion of m-government: challenges and future directions for research. In Working Conference on Virtual Enterprises (pp. 88-94). Berlin, Germany.

Al-khamayseh, S., Lawrence, E., \& Zmijewska, A. (2006). Towards understanding success factors in interactive mobile government, Second European Conference on Mobile Government, Brighton, England.

Almarashdeh, I., \& Alsmadi, M. (2016). Heuristic evaluation of mobile government portal services: An experts' review. In 2016 11th International Conference for Internet Technology and Secured Transactions (ICITST) (pp. 427-431), Barcelona, Spain.

Almarashdeh, I., \& Alsmadi, M.K. (2017). How to make them use it? Citizens acceptance of m-government. Applied Computing and Informatics, 13(2), 194-199.

Alotaibi, R., Houghton, L., \& Sandhu, K.(2016). Exploring the potential factors influencing the adoption of m-government services in Saudi Arabia: A qualitative analysis. International Journal of Business and Management, 11(8), 56-71.

Arslan, A. (2012). M-government service provisions among Turkish local governments. Internet Uygulamalarl ve Yönetimi Dergisi, 3(2), 5-26.

Bannister, F., \& R. Connolly, R. (2011). Trust and transformational government: a proposed framework for research. Government Information Quarterly, $28(2), 137-147$.

Bayrak, H. (2020). TUIKK hanehalkı bilişim teknolojileri kullanım araştırması, 18 Ocak 2020 tarihinde https://dijilopedi.com/2019-tuik-hanehalki- bilisimteknolojileri-kullanim-arastirmasi/ adresinden alındı.

Cole, D.A., \& Maxwell, S.E. (2003). Testing mediational models with longitudinal data: Questions and tips in the use of structural equation modeling. Journal of Abnormal Psychology, 112(4), 558-577.

Colesca, S. E. (2009). Understanding trust in e-government. Engineering Economics, 63(4), 7-15.

Çokluk, Ö., Şekercioğlu, G., \& Büyüköztürk, Ş. (2010). Sosyal Bilimler için Çok Değişkenli İstatistik SPSS ve LISREL uygulamalart. Ankara, Türkiye: Pegem Yayıncılık.

Çolak, M. (2020). Gizlilik ve Güvenlik, 18 Ocak 2020 tarihinde http://bilgisayarbilim.com/gizlilik-ve-guvenlik/ adresinden alındı.

Davis, F. (1989). A Technology acceptance model for empirically testing new end user information systems: theory and results (Doctoral dissertation). MIT Sloan School of Management, Cambridge, MA.

E-devlet Portal1, (2021). Mobil Hizmet Sayısı,12 Ocak 2021 tarihinde https://www.turkiye.gov.tr/ adresinden alındı.

El-Kiki, T., \& Lawrence, E. (2006). Mobile user satisfaction and usage analysis model of m-government services,

In Proceedings of EURO mGOV (pp. 91-102). Brington, United Kingdom.

Fornell, C., \& Larcker, D. F.(1981). Evaluating structural equation models with unobservable variables and measurement error, Journal of Marketing Research, 18(1), 39-50.

Gao ,S., Krogstie, J., \& Gransæther, P.A. (2008). Mobile services acceptance model. 2008 International Conference on Convergence and Hybrid Information Technology, IEEE (pp. 446-453). Daejeon, Korea (South).

Güler, M., \& Dövertaş, E. (2009). Elektronik devletten (e-devlet) mobil devlete (m-devlet) geçişte Türkiye'de yerel yönetim uygulamaları. Hitit Üniversitesi Sosyal Bilimler Enstitüsü Dergisi, 2(1), 25-49.

Gürses, F., \& Engin, M. (2016). Türkiye’de yerel yönetimlerde mobil devlet uygulamaları: büyükşehir belediyeleri üzerine ampirik bir araştırma. Süleyman Demirel Üniversitesi İktisadi ve İdari Bilimler Fakültesi Dergisi, 21(1), 223- 234.

Hung, S.Y.; Chang, C.M., \& Kuo, S. R. (2013). User acceptance of mobile e-government services: An empirical study. Government Information Quarterly, $30(1), 33-44$.

Ishengoma, F., Mselle, L., \& Mongi, H. (2019). Critical success factors for m-government adoption in Tanzania: A conceptual framework. The Electronic Journal of Information Systems in Developing Countries, 85(1), e12064.

Khasawneh, R.T., Rabayah, W. A., \& Abu-Shanab, E. A. (2013). E-government acceptance factors: trust and risk, In The 6th International Conference On Information Technology (ICIT 2013) (pp. 5-10). Amman, Jordan. 
Koivumäki, T., Ristola, A., \& Kesti, M. (2008). The effects of information quality of mobile information services on user satisfaction and service acceptance-empirical evidence from Finland, Behaviour ve Information Technology, 27(5), 375-385.

Kushchu, I., \& Kuscu, H. (2003). From e-government to m-government: facing the inevitable. In the 3rd European Conference on e-Government (pp.253260). MCIL Trinity College Dublin, Ireland.

Nunnally, J. C., \& Bernstein, I. H. (1994). The assessment of reliability. Psychometric Theory, 3(1), 248-292.

Önal, M. F. (2020). E-devlet kapıst istatistikleri ve değerlendirmeler, 20 Ocak 2020 tarihinde http://www.egovturkey.com/e-devlet-kapisi-istatistiklerive-degerlendirmeler-04032020 adresinden alındı.

Öztürkcan, S., Kasap, N., \& Eryarsoy, E. (2012). M-devlet kullanıcı kabul potansiyeli: kümeleme analizi ve karar ağacı yaklaşımı. Cumhuriyet Üniversitesi Íktisadi ve İdari Bilimler Dergisi, 13(2), 87-111.

Rana, N., Janssen, M., Sahu, G.P., Baabdullah, A., \& Dwivedi, Y. (2019). Citizens' perception about m-government services: Results from an exploratory survey. In Proceedings of the 52nd Hawaii International Conference on System Sciences (pp. 3356-3365). Hawaii, USA.

Rehman, M., Kamal, M., \& Esichaikul, V. (2012). Determinants of trust in e-government adoption: a case study of Pakistan. Proceedings of the Eighteenth Americas Conference on Information Systems (pp.1-12). Seattle, Washington, USA.

Roubah, K., Qurban, H., Al-Qirim, N., \& Tarhini, A. (2018). Understanding mobile government success in an arab country: findings from a qualitative study. Issues in Information Systems, 19(2), 185-198.

Sandy, G.A., \& McMillan, S. (2005). A success factors model for m-government. EURO mGOV (pp. 349-358). Brighton, England.

Saxena, S. (2017). Enhancing ICT infrastructure in public services: factors influencing mobile government (m-government) adoption in India. The Bottom Line, 30(4), 279-296.

Shareef, M. A., Archer, N., \& Dwivedi, Y.K. (2012). Examining adoption behavior of mobile government. Journal of Computer Information Systems, 53(2), 39-49.

Tabachnick, B.G., Fidell, L.S., \& Osterlind, S. J. (2007). Using Multivariate Statistics. Boston, MA, USA: Pearson Publishing.

Tan, G. W. H., Ooi, K.B., Sim, J.J., \& Phusavat, K. (2012). Determinants of mobile learning adoption: an empirical analysis. Journal of Computer Information Systems, 52(3), 82-91.

Üste, R. B., \& Güzel, B. (2012). From e-governance through m-governance: Turkey applications. International Journal of eBusiness and eGovernment Studies, 4(1), 47-58.

Veeramootoo, N., Nunkoo, R., \& Dwivedi, Y.K. (2018). What determines success of an e-government service? Validation of an integrative model of efiling continuance usage. Government Information Quarterly, 35(2), 161-174.

Venkatesh, V., \& F.D. Davis, F.D. (2000). A theoretical extension of the technology acceptance model: Four longitudinal field studies. Management Sciences, 46(2), 186-204.

Venkatesh, V., Morris, M.G., Davis, G.B., \& Davis, F.D. (2003). User acceptance of information technology: Toward a unified view. MIS Quarterly, 27(3), 423-478.

Wang, H.J., \& Lo, J. (2013). Determinants of citizens' intent to use government websites in Taiwan. Information Development, 29 (2), $123-137$.

Wang, C. (2014). Antecedents and consequences of perceived value in mobile government continuance use: An empirical research in China. Computers in Human Behavior, 34, 140-147.

Wang, Y.S. (2008). Assessing e-commerce systems success: a respecification and validation of the Delone and Mclean model of IS success. Information Systems Journal, 18(5), 529-557.

Yıldırım, F., \& Panayırcı, U.C. (2012). Governmental mobile technology usages during promotion efforts of reaching their citizens. International Journal of eBusiness and eGovernment Studies, 4(1), 35-43. 
